\title{
RETRACTED ARTICLE: Waveguide dispersion characteristics of graded/linearly chirp type's refractive index profile of planar slab optical waveguide by using the modified finite element method
}

\author{
Sanjeev Kumar Raghuwanshi • Santosh Kumar
}

Received: 22 December 2011 / Accepted: 10 July 2014 / Published online: 12 August 2014

(C) The Optical Society of India 2015

The article has been withdrawn by Journal of Optics as Editor-in-Chief and Editorial Board have determined that the material presented in this article is similar to an article that was published by the same authors in Optik - International Journal for Light and Electron Optics (doi:10.1016/j.ijleo.2014.05.049).

The article has been withdrawn by Journal of Optics as Editor-in-Chief and Editorial Board have determined that the material presented in this article is similar to an article that was published by the same authors in Optik - International Journal for Light and Electron Optics (doi:10.1016/ j.ijleo.2014.05.049).

S. K. Raghuwanshi $(\bowtie) \cdot$ S. Kumar

Department of Electronics Engineering, Indian School of Mines

Dhanbad, Dhanbad 826004, India

e-mail: sanjeevrus@yahoo.com

S. Kumar

e-mail: santoshrus@yahoo.com 